\title{
Childhood extraordinary daytime urinary frequency-a case series and a systematic literature review
}

\author{
Manuela Bergmann - Teresa Corigliano • Iris Ataia • \\ Raffaele Renella • Giacomo D. Simonetti • \\ Mario G. Bianchetti • Rodo O. von Vigier
}

Received: 28 July 2008 /Revised: 20 October 2008 / Accepted: 23 October 2008 / Published online: 18 December 2008

(C) IPNA 2008

\begin{abstract}
Childhood extraordinary daytime urinary frequency is likely a common but underreported condition characterized by daytime frequent voiding and typically not linked with complaints of burning, urinary incontinence, altered urinary stream, changes in the nighttime voiding pattern, excessive fluid intake and excessive urinary volume. To determine the features and outcome of extraordinary daytime urinary frequency, we report our experience with 14 children and the results of a formal systematic analysis of peer-reviewed English-language literature on this topic. Nineteen case series were found (together with 16 mostly pertinent comments), with each case series providing details on from one to 119 children. On the basis of our experience and the findings of our systematic analysis, we conclude that, in general practice, extraordinary daytime urinary frequency is a common cause of urinary frequency, that the age of such patients is, on average, 6 years and that the micturation abnormalities persist for an average of 6 months. The results of this review must be viewed with an understanding of the
\end{abstract}

Manuela Bergmann and Teresa Corigliano contributed equally to the work.

M. Bergmann · T. Corigliano $\cdot$ R. Renella $\cdot$ M. G. Bianchetti Department of Pediatrics,

Mendrisio and Bellinzona Hospitals and University of Bern,

Bern, Switzerland

M. Bergmann - T. Corigliano · I. Ataia • G. D. Simonetti •

R. O. von Vigier $(\square)$

Pediatric Nephrology, University Children's Hospital Bern

Inselspital and University of Bern,

3010 Bern, Switzerland

e-mail: rodo.vonvigier@hotmail.com limitations of the analysis process, which incorporated data exclusively from case series.

Keywords Child - Extraordinary daytime urinary frequency Pollakiuria $\cdot$ Urinary tract infections . Urination disorders

\section{Introduction}

On occasion, previously healthy children unexpectedly change a normal daytime voiding pattern to one with episodes of increased voiding frequency occurring during part or all of each day. Voiding occurs at intervals varying from once every 5 min to once per hour. In these children, daytime frequent voiding is typically not linked with complaints of burning or pain, urinary incontinence, altered urinary stream, changes in the nighttime voiding pattern, excessive fluid intake and excessive urinary volume and/or pathological physical examination, urinalysis or urine culture. This striking condition, first reported more than 40 years ago by Stephens et al. as "sham" urinary tract infection [1], is recognized under various terms: pollakiuria, daytime urinary frequency (syndrome) of childhood, extraordinary (daytime) urinary frequency (syndrome) (in children), (syndrome of) isolated (extraordinary) daytime (urinary) frequency of childhood or daytime urinary frequency and urgency (syndrome) (of childhood). In some reports children with both daytime frequency and dysuria were analyzed separately and designated as suffering from frequency-dysuria syndrome [2].

We report our experience with 14 previously unreported children affected by extraordinary daytime urinary frequency (EDUF) and the results of a formal systematic analysis of 
the peer-reviewed scientific literature that deals with children affected by EDUF.

\section{Case series}

Over a period of 8 years, between 2000 and 2007, the diagnosis of EDUF was made by one of us (R.O.V.) in 14 consecutive Caucasian children (nine boys and five girls; age at onset of symptoms 3.7-11.3 years; median age 5.3 years) referred to the Division of Pediatric Nephrology, University of Bern, Switzerland, for diagnostic work-up (Table 1). The patients presented with a history of increased frequency of urination $(1-12 / \mathrm{h}$, median frequency $3 / \mathrm{h}$ ) lasting 1-30 months (median 4.5 months) prior to evaluation. Five patients additionally presented with nocturia (1-4/ night, median 2.5/night). Time of onset of increased frequency of urination was evenly distributed throughout the year. A thorough medical and physical history with emphasis on voiding patterns and emotionally stressful situations at kindergarten, school or within the family was elicited for all patients, and a physical examination, urinalysis, urine culture and renal ultrasound were performed. None of the children had a history of change in the color or odor of urine, urethral or vaginal discharge or abnormalities in the initiation, force or direction of their urinary stream. In addition, none had polydipsia, abnormal bowel habits, history of sexual abuse, high blood pressure or an abnormal physical examination. Developmental disabilities in the form of attention deficit hyperactivity and cognitive-motor retardation were each present in one child. Two children were affected by depression and restless leg syndrome, respectively. In 11 cases the parents were able to identify an emotional or psychological trigger occurring just before the onset of urinary frequency. In two children, the tendency towards an increase in the frequency of urination had disappeared just before evaluation; in the remaining children the complaints persisted 0-20 months (median 1 month) after evaluation and counseling.

\section{Materials and methods}

\section{Definitions}

According to the International Children's Continence Society [3], EDUF is defined as: (1) a child voiding at least once hourly and with small volumes during the

Table 1 Clinical features in 14 children with extraordinary daytime urinary frequency

\begin{tabular}{|c|c|c|c|c|c|c|c|c|}
\hline \multirow[t]{2}{*}{ Number } & \multirow[t]{2}{*}{$\begin{array}{l}\text { Age } \\
\text { (years) }\end{array}$} & \multirow[t]{2}{*}{ Gender } & \multirow{2}{*}{$\begin{array}{l}\text { Micturation } \\
\text { frequency } \\
\text { (per hour) }\end{array}$} & \multirow{2}{*}{$\begin{array}{l}\text { Nocturia } \\
\text { frequency } \\
\text { (per night) }\end{array}$} & \multicolumn{2}{|c|}{$\begin{array}{l}\text { Duration of disturbance } \\
\text { (months) }\end{array}$} & \multirow[t]{2}{*}{$\begin{array}{l}\text { Possible emotional or } \\
\text { psychological trigger }\end{array}$} & \multirow[t]{2}{*}{$\begin{array}{l}\text { Pre-existing } \\
\text { condition }\end{array}$} \\
\hline & & & & & $\begin{array}{l}\text { Before } \\
\text { evaluation } \\
\text { counseling }\end{array}$ & $\begin{array}{l}\text { After } \\
\text { evaluation and } \\
\text { counseling }\end{array}$ & & \\
\hline 1 & 3.7 & Male & 2 & - & 30 & 4 & Birth of a sibling & \\
\hline 2 & 3.8 & Female & 12 & $3-4$ & 12 & 1 & $\begin{array}{l}\text { Rivalry with the twin } \\
\text { brother }\end{array}$ & \\
\hline 3 & 4.5 & Male & 12 & - & 1 & $-^{\mathrm{a}}$ & $\begin{array}{l}\text { Mother-child separation } \\
\text { following maternal } \\
\text { employment }\end{array}$ & \\
\hline 4 & 4.5 & Male & 3 & - & 7 & $-^{\mathrm{b}}$ & & $\begin{array}{l}\text { Attention deficit } \\
\text { hyperactivity } \\
\text { disorder }\end{array}$ \\
\hline 5 & 4.3 & Male & 3 & - & 3 & $-^{\mathrm{a}}$ & Severe disease of a brother & \\
\hline 6 & 4.8 & Female & 2 & $2-3$ & 5 & 20 & & $\begin{array}{c}\text { Restless leg } \\
\text { syndrome }\end{array}$ \\
\hline 7 & 5.2 & Male & 3 & - & 5 & 2 & $\begin{array}{l}\text { Brother undergoing major } \\
\text { surgical procedure }\end{array}$ & \\
\hline 8 & 5.4 & Male & 4 & 1 & 2 & 0.5 & & \\
\hline 9 & 5.8 & Male & 8 & 1 & 3 & 1 & Fall from balcony & Mental retardation \\
\hline 10 & 6.0 & Female & 3 & - & 4 & 1 & Familial conflict & \\
\hline 11 & 8.3 & Female & 2 & - & 6 & 1 & Depression & \\
\hline 12 & 9.8 & Male & 2 & - & 1 & 1 & Sports injury & \\
\hline 13 & 11.0 & Female & 1 & - & 12 & 1 & Educational conflicts & \\
\hline 14 & 11.3 & Male & 2 & $2-3$ & 4 & 0.5 & Child's bedroom changed & \\
\hline
\end{tabular}

${ }^{a}$ Disturbance disappeared before evaluation

${ }^{\mathrm{b}}$ Disturbance disappeared immediately after evaluation and counseling 
daytime only; (2) incontinence is not a usual or necessary ingredient in the condition; (3) nocturnal bladder behavior is normal for the age of the child; (4) the condition occurs from the age of daytime bladder control or 3 years. In some publications, the term frequency-dysuria syndrome has been used for children with both frequency and dysuria. This classification was adopted in the analysis reported here according to the terminology used in respective publications.

Data sources- types of data

Two of us (M.B., T.C.) independently analyzed the reports dealing with children affected by EDUF or frequencydysuria using the United States National Library of Medicine database (February 2008), personal files and reference lists through January 1960 as sources of data. Considering that little information is available, all categories of reports published as full-length articles or letters in peer-reviewed English-language scientific publications were considered. To conduct the final analysis, we retained 19 case series published either as full-length articles or as letters [4-22], with each providing details on from one to 119 children, and 16 comments or suggestions that were mostly pertinent to this subject [2, 23-37].

\section{Results}

Extraordinary daytime urinary frequency

In addition to the 14 children included in the case series reported here, we also include 499 children [4-7, 9-20, 22] with EDUF (57\% boys) ranging in age from 2.0 to 14 years (median age 5.8 years) that have been the subject of previous publications.

\section{Prevalence and incidence}

No report directly addressed the prevalence of daytime urinary frequency in childhood. However, two authors compared the incidence of daytime urinary frequency with the incidence of urinary infections: Bass, a general pediatric practitioner, states that during a 1-year period, he saw 13 children with EDUF and eight with lower urinary tract infections [11]. Cohen treated 15 patients with daytime urinary frequency and 16 with urinary infection in a 33-month interval [13].

On the other side among 226 children with voiding dysfunction evaluated by Hellerstein and Linebarger, detrusor instability was found in 175, EDUF in 20, infrequent voiding in 13 , monosymptomatic daytime wetting in ten and more rare voiding disorders in the remaining children [20].

\section{Seasonal incidence}

Koff and Byard noted that in 35 of 43 children daytime urinary frequency presented during the cold weather months (October to April). These authors suggested that the disturbance was caused by "heightened bladder sensitivity". However, they recognized that "this also is the time when children are in school and responding to a variety of psychological stresses" [5]. In contrast, other authors have reported a total of 231 cases that were evenly distributed throughout the year $[10,14,16,17,22]$.

\section{Clinical presentation}

In addition to the increased frequency of urination, a number of authors of earlier publications reported micturation abnormalities, alone or in combination, in some of children with EDUF, as summarized in Table 2.

\section{Triggers and/or causes}

Psychosocial problems or recent emotional stress, abnormal urine composition and infections have been viewed as possible triggers or causes of EDUF.

Psychosocial problems or recent emotional stress In previous reports $[4,9-11,13,14,16,19,22]$ and in our case series, possible psychosocial difficulties or areas of anxiety were noted in 95 of 194 (49\%) affected children. In a comment published approximately 20 years after his original report, Asnes states that his experience through the years in examining children with daytime urinary

Table 2 Micturation abnormalities other than pollakiuria reported in patients with extraordinary daytime urinary frequency

\begin{tabular}{|c|c|c|c|}
\hline Micturation abnormalities & $n /$ total & Percentage & References \\
\hline Dysuria & $15 / 82$ & 18 & $5,6,9,14,20$ \\
\hline Nocturia & $50 / 171$ & 29 & $5-7,9,10,14$ \\
\hline Pre-existing nocturnal enuresis & $9 / 89$ & 10 & 5,10 \\
\hline Secondary nocturnal enuresis & $16 / 103$ & 15 & $6,9,12-14$ \\
\hline Daytime incontinence $^{\mathrm{a}}$ & $11 / 41$ & 27 & 9,14 \\
\hline
\end{tabular}

${ }^{\mathrm{a}}$ Initially (or very mild) 
frequency has led to the conclusion that psychogenic factors are significant in the majority of cases [31].

Other authors $[5-7,15]$ did not specifically address the psychosocial difficulties or the areas of anxiety possibly triggering daytime urinary frequency in their patients, although in their discussion they do mention that the etiology of daytime urinary frequency may be predominantly behavioral or stress related. In the individual reports, the part of children with psychosocial difficulties or areas of anxiety varied between 0 and $100 \%$. The most commonly reported stressor factors were problems at school, severe illness or death of a family member, parental divorce, relocating and birth of a sibling. One report observed the occurrence of EDUF in refugee families; as a matter of fact, children from these families have a significant risk of developing emotional disturbances because they are often exposed to violence, forced displacement and multiple losses [22]. Zoubek et al. [10] noted striking similarities between daytime urinary frequency and excessive eye blinking, a motor tic disorder.

Metabolic causes (abnormal urine composition) Hypercalciuria was reported in 21 of 96 patients (four reports: [9, $14,15,17])$. In contrast, in two other studies, the urine calcium over creatinine ratio was normal in 68 EDUF patients $[16,20]$; taken together the urinary calcium over creatinine ratio was found to be increased in 21 of 164 children (13\%). Corigliano noted the ingestion of large quantities of oxalate-rich beverages in five of 26 patients [22]. In two reports, daytime urinary frequency was associated with a tendency towards an acidic urinary $\mathrm{pH}$ (five of ten patients [9]) and the liberal ingestion of acidic fruit juices (orange, apple, grape, grapefruit) and tomato juice (four of 26 patients [22]). However, urinary $\mathrm{pH}$ was normal in a total of 27 patients reported in two other studies $[6,7]$.

Infectious causes Daytime urinary frequency followed an upper respiratory tract illness in 21 of total 58 patients in three reports $[6,7,14]$. This impression is shared in a comment [24]. An increase in the frequency of urination sometimes occurs in children with neuropsychiatric disorders associated with group A streptococcal infection, but in the cases reported by Corigliano et al., the onset of diurnal frequency of urination was never preceded by a streptococcal infection [22].

Infestation with Enterobius vermicularis may cause urinary frequency in girls, but a perirectal "tap test" was reported to be negative in four reports $[6,7,15,22]$. Robson and Leung found that the increased urination frequency developed coincidental with swimming lessons in four of their 31 patients [14]. These authors performed urine tests for mycoplasma and ureaplasma in 27 children and for cytomegalovirus and adenovirus in 25: cytomegalovirus was isolated in three children of whom one child also had adenovirus, and ureaplasma was isolated from one child. The authors of two comments confirm that mycoplasma, ureaplasma and perhaps even viruses may be responsible for EDUF [23, 25].

\section{Management}

Reassurance and emotional support Most reports suggest that reassurance of the patient and his or her parents regarding the self-limited and benign nature of the condition and observation are critical and helpful [5-7, $10,11,13,14,16-20,22]$. Many authors also state that if a specific trigger event or stressful situation can be identified, efforts to resolve it may be worthwhile. After the precipitating stressful event is unearthed and discussed, parents relax: there is less concern about the symptom, less attention is paid to it and to the child and the symptom gradually clears $[4,10,11,13,16,22]$.

Dietary approaches It has been suggested that a chemical pathogenesis is operative in these children: excessive urinary calcium excretion, the liberal ingestion of acidic beverages or the consumption of large quantities of oxalaterich beverages. Affected patients have been counseled to ingest liberal amounts of water $[8,9,14,19]$, to restrict the intake of milk $[9,14]$, acidic beverages $[9,22]$ or oxalate rich-beverages [22]. Bladder irritants, such as caffeine [20], should be eliminated from the diet.

Drug management The non-steroidal antirheumatic drug indomethacin and anticholinergic agents have been studied or proposed for the treatment of symptoms of EDUF. In 30 Chinese children with EDUF, oral indomethacin dramatically decreased urinary frequency, whereas chloramphenicol failed to influence the frequent voiding [12]. The promising results [33] of this trial have not yet been confirmed.

Anticholinergic agents are widely used in children with over-active bladder [3]. In children with EDUF, the administration of anticholinergic agents is open to debate but has never been addressed in a well-designed trial. These agents were used in 13 of the 43 children reported by Koff and Byard [5] but were ineffective. In contrast, two comments favor treating children with severe and especially persisting daytime urinary frequency with anticholinergic drugs $[29,30]$.

Biofeedback In an uncontrolled report, the influence of biofeedback on the symptoms of 84 children with EDUF was analyzed. After 2-4 months of biofeedback, 72 (86\%) children were able to achieve a 2- to 4 -h voiding interval [18]. Two comments to this report stated that the benefit of 
biofeedback in EDUF deserves consideration in a welldesigned randomized trial $[35,36]$. Biofeedback was also found to positively influence the symptoms in a 10-year-old boy [19]. A number of relatively older children were found to benefit from the instructions to voluntarily delay voiding a few minutes once urgency was perceived [20].

\section{Outcome}

The duration of symptoms mostly varies from some days to several months, although they can last even for years. The duration calculated in 366 patients was, on average, 6 months $[4,7,10,12-16,18,19,22$, and our case series]. In 11 children, frequency persisted for more than 9 months but often tended to decrease or become intermittent $[10,30]$. An intermittent pattern was observed in seven of the 31 patients reported by Robson and Leung [14]. In one child [4], the disturbance persisted intermittently for 4 years. Recurrence is possible but rare [19]. In a 4-year old boy, daytime urinary frequency recurred after a remission of 12 months $[10,30]$ : the duration of symptoms was 1 and 8 months, respectively.

\section{Frequency-dysuria}

Three articles report on a total of 100 children living in the USA who had both extraordinary daytime urinary frequency and urinary burning (or pain) $[8,15,17]$. The condition, which has been called frequency-dysuria, affects children aged 2-14 years. Two case series including a total of 188 patients with either daytime urinary frequency $(n=96)$ or frequency-dysuria $(n=92)$ suggest that the frequencydysuria may be as frequent as isolated extraordinary daytime urinary frequency $[15,17]$. Psychosocial problems or recent emotional stress and hypercalciuria were the most frequently addressed triggers in patients with frequencydysuria $[15,17]$. The prevalence of hypercalciuria was similar in patients affected by isolated daytime urinary frequency and those affected by frequency-dysuria. Liberal fluid ingestion was recommended in all patients, with the addition of a thiazide diuretic to reduce urinary calcium excretion in a minority of the patients with frequencydysuria and hypercalciuria [15, 17].

Daytime urinary frequency in children with tic disorders

Nine Taiwan children (eight boys and one girl) aged between 4 and 19 years with active tic disorders (transient tic disorder, $n=5$; Tourette syndrome, $n=3$; chronic tic disorder, $n=1$ ) were found to have EDUF [21]. In addition to tic disorders and daytime urinary frequency obsessive compulsive behavior $(n=8)$, and self-injurious behavior, including nail biting or skin peeling $(n=4)$ was often observed in these patients. In these patients, the onset of tic disorder and diurnal frequency of urination was never preceded by a streptococcal infection, and the urinary calcium excretion was found to be normal. Recent emotional stress was found in only three of the nine children. However, triggering of urination by word suggestion was evident in six patients. Psychotherapy did not bring about any dramatic cessation of urinary frequency in these nine patients.

\section{Discussion}

The investigation reported here was conducted to increase the awareness of EDUF as a high degree of clinical suspicion is crucial to the diagnosis of this condition, which might well be overlooked and underreported [2]. Misdiagnosis may result in redundant investigations and unnecessary management, which can cause apprehension in the patients, in their parents and in the physicians.

The results of this and previous studies indicate that EDUF is common among children referred to pediatric nephrologists and urologists for diagnostic work up of voiding disorders or recurrent urinary tract infections. The average age of the affected patients is 6 years, and urinary frequency persists on average for 6 months. Unfortunately, the available data do not allow us to establish the cause of this condition.

Extraordinary daytime urinary frequency is indeed not an isolated condition but is associated with additional micturation abnormalities, including nocturia, pre-existing nocturnal enuresis, secondary nocturnal enuresis, diurnal incontinence and, in particular, dysuria in a number of the 513 patients supposed to suffer from isolated daytime urinary frequency. The failure to separately analyze this subset of patients and to include them in the group of patients with frequencydysuria, as a result of methodological issues in the published studies, supports the assumption that isolated EDUF, frequency-dysuria and daytime urinary frequency with tic disorders probably represent variants within a clinical spectrum of one single condition. This hypothesis is further supported by the fact that children with increased voiding frequency may sometimes lack language development skills needed to distinguish urinary frequency from urinary urgency and urinary burning or pain [38].

Psychosocial problems or recent emotional stress, abnormal urine composition and infections have been proposed as possible causes of EDUF. However, it is difficult to establish causality, given the case-series design chosen by the authors of the reports that deal with the condition [34].

Psychosocial problems or recent emotional stress The majority of authors find that psychosocial problems or 
Table 3 Conditions that deserve consideration in children presenting with increased voiding frequency suspected of suffering from extraordinary daytime urinary frequency (modified from [22])

Genitourinary tract infections and Enterobius vermicularis infestation Sexual abuse

Bladder overactivity

Polyuric conditions (e.g. diabetes mellitus, diabetes insipidus and nephrocalcinosis)

Drugs (e.g. some antihistamines, diuretics, theophylline, cisapride, psychotropic drugs)

Urolithiasis

Urinary tract obstruction

Pediatric neuropsychiatric disorder associated with group A streptococcal infection

emotional stress underlie most cases of EDUF. This impression is further supported by the similarity between EDUF and recurrent abdominal pain or motor tic disorders [9] and by the concurrent occurrence of tic disorders and daytime urinary frequency in a minority of patients [21]. Daytime urinary frequency, recurrent abdominal pain and tic disorders $[39,40]$ are currently considered to be physical symptoms that prompt to seek health care but which mostly remain unexplained after appropriate medical evaluation. They are also not linked to the "red flags" suggesting organic disease, such as recurrent fever, loss of appetite or energy and, in particular, nocturnal disturbances.

Abnormal urine composition A second proposed cause of EDUF is urinary over-saturation with the subsequent precipitation of poorly soluble waste salts. Unlike adults in whom urolithiasis is the most common manifestation, children with urinary over-saturation present predominantly with non-calculous lower urinary tract disturbances, including hematuria, frequency, urgency, dysuria, incontinence and suprapubic pain, likely because over-saturation and, subsequently, micro-crystallization irritate the cells that cover the surface of the lower urinary tract [41]. Risk factors for urinary over-saturation include low urine volume and $\mathrm{pH}$, hypercalciuria and hyperoxaluria. Therefore, concentrated urine, low urinary $\mathrm{pH}$, hypercalciuria and an increased dietary oxalate intake have been addressed in the pathogenesis of EDUF. The role of hypercalciuria has been overemphasized in two ways: first, because no author considered the fact that upper reference values for spot urinary calcium-to-creatinine ratio, a recognized and accurate marker for hypercalciuria, vary very strongly with age [42]; second and more importantly, oxaluria has a more profound effect on over-saturation than calciuria and, consequently, on the pathophysiology of stone disease [43]. Exposure to caffeine has also been associated with frequency. In addition to coffee, cola or chocolate drinks and black tea or ice-tea are major sources of caffeine.
Infections Some children with extraordinary daytime frequency had been in a swimming pool in the week preceding the manifestation, causing several authors to perform urine tests for mycoplasma, ureaplasma, adenovirus or cytomegalovirus, which in some cases were found to be positive. Unfortunately, this hypothesis has not been pursued. Finally, some authors noted that EDUF often followed an upper respiratory tract illness, suggesting that the condition might be included in the group of immunologically mediated post-infectious disorders.

Because researchers have used history, physical examination or laboratory testing as inclusion or exclusion criteria for EDUF, there are no studies that have evaluated the usefulness of clinical or laboratory data for identifying the condition. In our opinion, the diagnosis of EDUF is straightforward in a child with sudden onset of frequency of voiding, a previously normal bladder and bowel pattern, normal urinary stream, normal physical examination, normal complete urinalysis and negative urine culture. We advise a urinary tract ultrasound at least in those children who present with both daytime urinary frequency and some further micturation abnormalities, such as dysuria, nocturia or wetting.

The evaluation of children with EDUF also requires that the physician learns details surrounding the onset of frequency as this will possibly reveal the triggers for unusual stress within the family and/or changes in social circumstances. Since the habits of children who have been sexually abused are sometimes abnormal, the possibility that child maltreatment may be the cause of daytime urinary frequency deserves careful consideration (see Table 3 ). The examining physician should also be alert for significant

Table 4 Recommended management in children with extraordinary daytime urinary frequency

\section{Cognitive-behavioral intervention}

Reassurance regarding the functional, self-limited and benign nature of the condition (examination of the patient during regularly scheduled appointments)

Discussion (and counseling) about stressful situation

Referral to a psychologist (or a psychiatrist) when daytime frequency is accompanied by a serious individual or family pathology or when there are serious accompanying pathologic behaviors Diet

Liberal water ingestion

Reduce oxalate-rich beverages (black tea and ice tea), acid juices (orange, apple, grape, grapefruit or tomato) and caffeine (coffee, cola or chocolate drinks, black tea and ice-tea) where appropriate ${ }^{\mathrm{a}}$

Drug management (children with severe and long-lasting disturbances):

Indomethacin

Anticholinergic agent (oxybutinine, tolterodine) Biofeedback

\footnotetext{
${ }^{\mathrm{a}}$ We never restrict milk
} 
dietary factors, including a low intake of fluid and an excessive intake of acidic or caffeine- or oxalate-containing beverages.

The recommended management is summarized in Table 4 . Once the condition is recognized, it is critical that the physician provides reassurance to both the parents and child regarding the self-limited and benign nature of the condition as this usually forestalls the need for additional medical examinations. Stressful situations, such as the death of a relative, a sibling's illness or school problems, should be discussed and counseling provided as these actions often will result in abatement of the urinary symptoms. At our institute, all children with this problem are also counseled to ingest liberal amounts of water.

\section{References}

1. Stephens FD, Whitaker J, Hewstone AS (1966) True, false and sham urinary tract infections in children. Med J Aust 2:840-842

2. Watemberg N, Shalev H (1994) Daytime urinary frequency in children. Clin Pediatr (Phila) 33:50-53

3. Nevéus T, von Gontard A, Hoebeke P, Hjälmås K, Bauer S, Bower W, Jørgensen TM, Rittig S, Walle JV, Yeung CK, Djurhuus JC (2006) The standardization of terminology of lower urinary tract function in children and adolescents: report from the Standardisation Committee of the International Children's Continence Society. J Urol 176:314-324

4. Asnes RS, Mones RL (1973) Pollakiuria. Pediatrics 52:615-617

5. Koff SA, Byard MA (1988) The daytime urinary frequency syndrome of childhood. J Urol 140:1280-1281

6. Walker J, Rickwood AM (1988) Daytime urinary frequency in children. Br Med J 297:455

7. Gupta AK, Uppal SS, Salhan RN (1990) Daytime urinary frequency syndrome in childhood. Indian Pediatr 27:752-754

8. Alon U, Warady BA, Hellerstein S (1990) Hypercalciuria in the frequency-dysuria syndrome of childhood. J Pediatr 116:103-105

9. Robson WLM, Leung AK (1990) Daytime urinary frequency. Pediatrics 86:1004-1005

10. Zoubek J, Bloom DA, Sedman AB (1990) Extraordinary urinary frequency. Pediatrics 85:1112-1114

11. Bass LW (1991) Pollakiuria, extraordinary daytime urinary frequency: experience in a pediatric practice. Pediatrics 87:735737

12. Luo XZ (1992) Indomethacin treatment in children with daytime frequency of micturition. Pediatr Nephrol 6:445-447

13. Cohen HA, Nussinovitch M, Kauschansky A, Straussberg R, Ashkenasi A, Frydman M, Varsano I (1993) Extraordinary daytime urinary frequency in children. J Fam Pract 37:28-29

14. Robson WLM, Leung AK (1993) Extraordinary urinary frequency syndrome. Urology 42:321-324

15. Brock JW 3rd (1994) The frequency and frequency-dysuria syndromes of childhood: hypercalciuria as a possible etiology. Urology 44:411-412

16. Chen WF, Huang SC (1995) Pollakiuria: extraordinary daytime urinary frequency a common problem in pediatric practice. Changgeng Yi Xue Za Zhi 18:115-119
17. Parekh DJ, Pope JC IV, Adams MC, Brock JW 3rd (2000) The role of hypercalciuria in a subgroup of dysfunctional voiding syndromes of childhood. J Urol 164:1008-1010

18. Glazier DB, Ankem MK, Ferlise V, Gazi M, Barone JG (2001) Utility of biofeedback for the daytime syndrome of urinary frequency and urgency of childhood. Urology 57:791-793

19. Goraya JS (2003) Daytime urinary frequency managed with bladder stretch exercises. Indian Pediatr 40:582-583

20. Hellerstein S, Linebarger JS (2003) Voiding dysfunction in pediatric patients. Clin Pediatr (Phila) 42:43-49

21. Wang HS, Chang HL, Chang SW (2005) Pollakiuria in children with tic disorders. Chang Gung Med J 28:773-778

22. Corigliano T, Renella R, Robbiani A, Riavis M, Bianchetti MG (2007) Isolated extraordinary daytime urinary frequency of childhood: a case-series of 26 children in Switzerland. Acta Paediatr 96:1347-1349

23. Crowther P, Pead PJ, Pead L, Maskell R (1988) Daytime urinary frequency in children. Br Med J 297:855

24. Leung AK, Robson WLM (1988) Daytime urinary frequency in children. Br Med J 297:1047

25. Whitaker RH, Gray J, Taylor CED (1988) Daytime urinary frequency in children. Br Med J 297:1468

26. Bloom DA, Sedman A, Zoubek J (1990) Daytime urinary frequency. Pediatrics 86:1004-1005

27. García Nieto V, Castro Díaz D, Gómez de la Rosa JL (1990) Urodynamics and hypercalciuria. J Pediatr 117:838

28. Alon U, Warady BA, Hellerstein S (1990) Urodynamics and hypercalciuria. J Pediatr 117:838

29. Colodny AH (1991) Extraordinary urinary frequency. Pediatrics $87: 582$

30. Bloom DA, Sedman A, Zoubek J (1991) Extraordinary urinary frequency. Pediatrics 87:582

31. Asnes RS, Mones RL (1991) Extraordinary urinary frequency. Pediatrics 87:953

32. Bloom DA, Sedman AB, Zoubek J (1991) Extraordinary urinary frequency. Pediatrics 87:953

33. Meadow SR (1993) Indomethacin treatment in children with daytime frequency micturition. Pediatr Nephrol 7:240

34. Seeman PD, Kiser WR (1994) Urinary frequency in children. J Fam Pract 38:13

35. de Gier RPE (2001) Utility of biofeedback for the daytime syndrome of urinary frequency and urgency of childhoodeditorial comment. Urology 57:793-794

36. Glazier DB, Ankem MK, Ferlise V, Gazi M, Barone JG (2001) Utility of biofeedback for the daytime syndrome of urinary frequency and urgency of childhood-reply by the authors. Urology 57:794

37. Robson WLM, Leung AK, Gangemi DJ (1994) Daytime urinary frequency. Clin Pediatr (Phila) 33:381

38. Cattell WR, Brooks HL, McSherry MA, Northeast A, O'Grady F (1975) Approach to the frequency and dysuria syndrome. Kidney Int Suppl 4:S138-S143

39. Thiessen PN (2002) Recurrent abdominal pain. Pediatr Rev 23:39-46

40. Golden GS (1987) Tic disorders in childhood. Pediatr Rev 8:229-234

41. Vezzoli G, Soldati L, Gambaro G (2008) Hypercalciuria revisited: one or many conditions. Pediatr Nephrol 23:503-506

42. Matos V, van Melle G, Boulat O, Markert M, Bachmann C, Guignard JP (1997) Urinary phosphate/creatinine, calcium/creatinine, and magnesium/creatinine ratios in a healthy pediatric population. J Pediatr 131:252-257

43. Holmes RP, Kennedy M (2000) Estimation of the oxalate content of foods and daily oxalate intake. Kidney Int 57:1662-1667 